
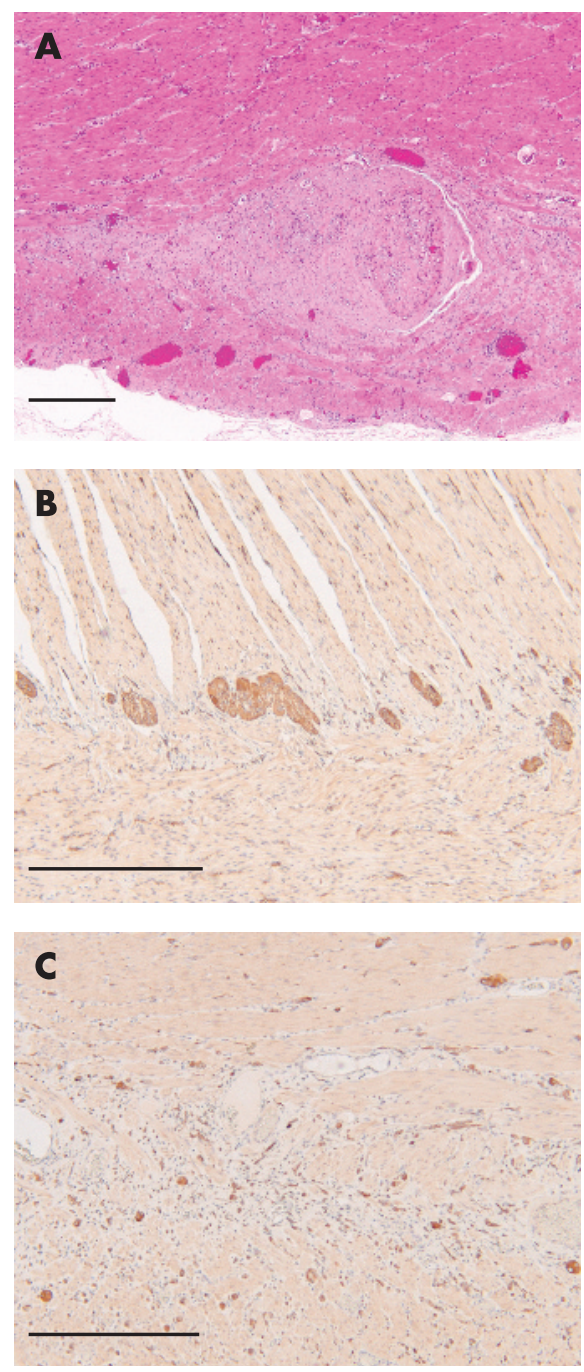

Figure 1 (A) Haematoxylin and eosin stained section showing hyperplastic nerves within the myenteric plexus. ( $B, C)$ Immunocytochemistry with an antibody to neuron specific enolase. (B) Ganglion cells can be seen distributed between the inner and outer layers of the muscularis externa at the resection margin. (C) Within the distended section of colon, there is loss of ganglion cells from the myenteric plexus, together with neurons scattered throughout the muscularis externa. Scale bar is $500 \mu \mathrm{m}$.

The persistent symptoms and electrophysiological abnormalities in our patient suggests more widespread involvement of the enteric nervous system. We suggest that diffuse abnormalities of the gastrointestinal autonomic nervous system may occur, in a similar way to other peripheral nerves, ${ }^{6}$ in NFl, and this possibility should be considered when patients present with what appears to be "functional bowel problems".

\section{O Hanemann}

Clinical Neurobiology, Institute of Biomedical and Clinical Science, Peninsula Medical School, Plymouth,

UK

C Hayward

Department of Gastroenterology, Derriford Hospital, Plymouth, UK

D A Hilton

Department of Histopathology Derriford Hospital, Plymouth, UK
Correspondence to: C Oliver Hanemann, Clinical Neurobiology, Institute of Biomedical and Clinical Science, Peninsula Medical School, The John Bull Building, Tamar Science Park, Research Way, Plymouth PL6 8BU, UK; Oliver.Hanemann@pms.ac.uk

doi: 10.1136/jnnp.2007.120451

Competing interests: None.

\section{References}

1 Gutmann DH, Aylsworth A, Carey JC, et al. The diagnostic evaluation and multidisciplinary management of neurofibromatosis 1 and neurofibromatosis 2. JAMA 1997;278:51-7.

2 Pinsk I, Dukhno O, Ovnat A, et al. Gastrointestinal complications of von Recklinghausen's disease: two case reports and a review of the literature. Scand J Gastroenterol 2003:38:1275-8.

3 Fuller CE, Williams GT. Gastrointestinal manifestations of type 1 neurofibromatosis (von Recklinghausen's disease). Histopathology 1991;19:1-11.

4 Feinstat T, Tesluk H, Schuffler MD, et al. Megacolon and neurofibromatosis: a neuronal intestinal dysplasia. Case report and review of the literature. Gastroenterology 1984:86:1573-9.

5 Carney JA, Go VL, Sizemore GW, et al. Alimentarytract ganglioneuromatosis. A major component of the syndrome of multiple endocrine neoplasia, type $2 b$. N Engl J Med 1976;295: 1287-91.

6 Ferner RE, Hughes RA, Hall SM, et al. Neurofibromatous neuropathy in neurofibromatosis 1 (NF1). J Med Genet 2004;41:837-41.

\section{BOOK REVIEWS}

\section{An introduction to the life and work of John Hughlings Jackson with a catalogue raisonné of his writings}

George York, David Steinberg. London: The Wellcome Trust Centre for the History of Medicine, 2006, £35.00, pp 139. ISBN 0 95484191

The name Hughlings Jackson still has considerable currency with neurologists of all interests, but his name is also widely known within psychiatry. This may be because he was perhaps one of the first neuropsychiatrists, someone who tried to understand the development of symptoms following cerebral lesions, but the symptoms also included abnormal mental states.

This little book gives a very succinct account of his life, but also of his neurological model. It is one of the clearer descriptions of Hughlings Jackson's principles this reviewer has read, and they only take up the first 30 pages of the text. Following that there is a catalogue of all of the known writings of Hughlings Jackson from 1861 through to 1909 , and then appendices of some published work, essentially pamphlets, some of which were circulated privately, and also unpublished documents which reside in the Rockefeller Medical Library of the National Hospital for Neurology and Neurosurgery.

This is a most useful and nicely produced book for anybody who would like an introduction to Hughlings Jackson's works, but is essential for Jacksonian Scholars.

This reviewer would merely cavil with the failure in the discussion of Hughlings Jackson's work to appreciate his interest in mental phenomena, with overemphasis on a view that Hughlings Jackson only considered the nervous system as a sensory-motor machine. Although it is known that Jackson favoured a psychophysical parallelism (the doctrine of concomitance) and avoided metaphysical explanations for scientific phenomena, rejecting unconscious mental states, his interest in psychiatry was considerable. This was stimulated by Daniel Hake Tuke and Thomas Laycock, and when he was at the National Hospital he visited the Bethlem Hospital and did ward rounds with Thomas Savage. Furthermore, he closely collaborated with James Crichton Browne at the West Riding Lunatic Asylum.

An outline of his thinking, still so important for neurology and psychiatry, can be gleaned from this useful book. As his obituarist Golla remarked "(Hughlings Jackson's) fundamental conception of the real significance of symptoms as the evidence of release of control is never lost sight of, and provides the clue to much that has been hopelessly entangled by the irrational attribution of positive symptoms to nervous matter that has undergone destruction".

M R Trimble

\section{The human brain and its disorders}

Edited by D Richards, T Clark, C Clarke. Oxford: Oxford University Press, 2007, pp 379. ISBN 9780199299843

This is an introductory textbook of neurological and psychiatric disorders with essential information about the structure and function of the normal brain. It has 379 pages divided into 16 chapters, 12 of which deal with clinical categories, including cerebrovascular diseases, epilepsy, Alzheimer's disease and related disorders, other neurodegenerative conditions, brain infections, multiple sclerosis, headache and chronic pain, neurosurgery, anxiety and related disorders, mood disorders, schizophrenia and related psychoses, psychoactive substance and addiction.

The first four chapters are devoted to basic aspects of neuroscience: structure, function, genomics of brain diseases and basic psychiatric concepts. Although each chapter is very concise, it contains fairly new topics, for example, vaccination therapy for Alzheimer's disease. There are many contrivances such as emboldened, coloured key words with definitions provided in the glossary. Each chapter starts with an introduction, highlighted by key points, self-check questions, case studies, extension boxes and followed by summary and further reading. The chapters are extensively cross referenced. Descriptions are concise, and figures and schema are suitably placed, which help readers to understand the book. In addition, there is a very kind explanation on how to use the book in the preface.

One of its features is the heads of the sections in the chapters written in interrogative sentences, which makes the book very familiar to readers, and provides the feeling that the reader has got the answers after having read that section or chapter. The only shortcoming is that the plate section is inserted in the middle of the chapter on multiple sclerosis. It should be at the end of the book.

Finally, this is a very user friendly introductory textbook of neuroscience. I recommend this book, particularly to non-MD junior neuroscientists, because most chapters are devoted to neurological and psychiatric disorders. The book may also be very useful to first or second year medical students who are interested in neuroscience.

Hidehiro Mizusawa 